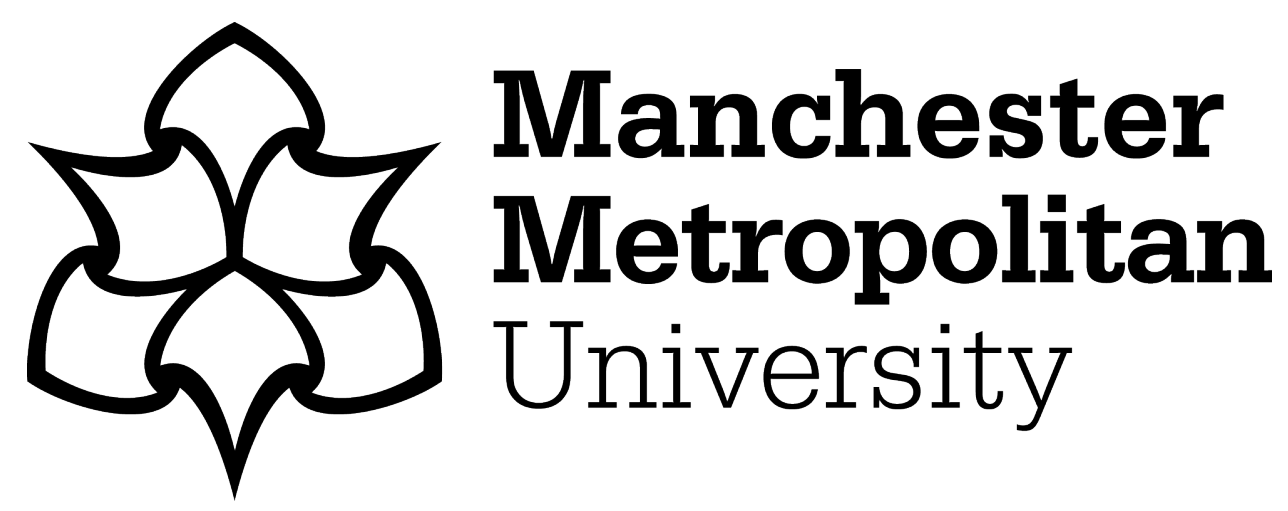

Orr, M and Inoue, Y ORCID logoORCID: https://orcid.org/0000-0002-19836217 (2020) Practitioner perspectives of legacy: insights from the 2015 Pan Am Games. Qualitative Research in Sport, Exercise and Health, 12 (5). pp. 717-729. ISSN 2159-676X

Downloaded from: https://e-space.mmu.ac.uk/624321/

Version: Accepted Version

Publisher: Taylor \& Francis

DOI: https://doi.org/10.1080/2159676X.2019.1673468

Please cite the published version 
RUNNING HEAD: PRACTITIONER PERSPECTIVES OF LEGACY

Practitioner Perspectives of Legacy: Insights from the 2015 Pan Am Games

July 2019

word count: 7029

Please cite this article as: Orr, M., \& Inoue, Y. (in press). Practitioner perspectives of legacy:

Insights from the 2015 Pan Am Games. Qualitative Research in Sport, Exercise and Health. 


\begin{abstract}
Although legacy frameworks exist in academia and legacies are oft discussed in relation to publicly- and privately-funded events, there remains a dearth of knowledge on practitioner conceptualizations of the concept. A case study of the Toronto 2014 Pan Am and Parapan Am Games was conducted using semi-structured interviews with event organizers and city officials to understand how practitioners conceptualize legacies, and what their goals are in relation to legacies. The findings show that organizers conceptualize legacies as solely positive, and include Games-time impacts and outcomes as part of the legacy. The positive frame supports the three central legacy goals: justifying public spending on events, boosting public support for event hosting, and advancing city development goals through event hosting. This research contributes to the discourse on event legacy and takes an important step in expanding understandings of practitioner conceptualizations of legacy.
\end{abstract}

Keywords: legacy, sport, event, practitioner, planning 


\section{Practitioner Perspectives of Legacy: Insights from the 2015 Pan Am Games}

\section{Introduction}

Sport events are expensive endeavours, usually funded by tax dollars. With many competing interests for public funding, event spending is frequently met with criticism from the media and host-city residents, which has led many cities to withdraw bids (Preuss 2015). Event legacies are often advanced by host committees and local officials as justification for spending on events (Gratton and Preuss 2008; Leopkey and Parent 2016; Thomson, Cuskelly, Toohey, Kennelly, Burton and Fredline 2018). Even though both academics and practitioners have been using the term event legacy for over thirty years (Leopkey and Parent 2012; Preuss 2015), a thorough understanding of what this term precisely represents has been lacking. This paper examines perspectives of legacy and highlights the key functions of the concept for practitioners.

Academics frequently reference the conceptualization of legacy presented by Preuss (2007) that identifies five dimensions of legacy: positive/negative, tangible/intangible, planned/unplanned, time, and space (Thomson, Schulenker, and Schulenkorf 2013). However, two recent studies of Canadian sport events have shown that practitioners, such as event organizers, members of sport governing bodies, and city officials, may not conceptualize legacies in the same way (Orr and Jarvis 2018; Sant, Mason and Hinch, 2013). These studies found practitioners' perspectives of legacies includes only the positive pole, although legacies are defined as including both positive and negative poles in the academic literature (Pavoni 2015; Preuss 2007). There remains four dimensions of legacy, as conceptualized by Preuss (2007), that have yet to be examined from a practitioner perspective; this examination could reveal elements that are more or less important to practitioners which could inform future academic research on this topic. 
The purpose of this study is twofold: (a) to explore how practitioners conceptualize legacies of large-scale events, and (b) to understand the goals that practitioners have for legacies, or what they seek to achieve through legacies. This study seeks to contribute to the ongoing discourse of event legacy by exploring the legacies of events from the perspective of those who are most directly engaged with them: event organizers.

\section{Event Legacies}

Event legacies have been planned, managed, and studied since the 1900s (Chappelet 2012). In the last decade, research on event legacies has grown in popularity and scope to include eleven types of legacy including political, economic, infrastructural, sport, and so on (Thomson et al. 2018). Scholars have commonly accepted and referenced Preuss's (2007) conceptualization of event legacy: 'all planned and unplanned, positive and negative, tangible and intangible structures created for and by a sport event that remain longer than the event itself' (211). This conceptualization includes five dimensions of legacy: space (i.e. local or global), planning (i.e. planned or unplanned), tangibility (i.e. tangible or intangible), positivity and negativity, and time (i.e. short-term or long-term).

Thomson et al. (2013) conducted a full review of legacy research conducted between 1992 and 2008 and identified four dimensions of legacy that are consistent throughout the academic literature. These dimensions were planning, time, positive/negative, and place (local/global). The only dimension from Preuss's model that was absent from this review was the tangible/intangible piece; however, the legacies presented in Thomson et al. (2013) included both tangible and intangible examples. The latest developments in legacy theorizing extend Preuss's (2007) earlier works by proposing that the scale of legacy is determined by the overall changes to the host city in terms of infrastructure, policy, networks, and emotions (Preuss 2015); and that 
legacies can be classified based on whether they materialized or not, and if so, whether they were motivated by the event, or accelerated by the event (Kassens-Noor et al. 2015). These developments do not countervail the dimensions of legacy proposed in Preuss's (2007) earlier work.

Scholars have called for a shift towards the use of 'leveraging', instead of legacy (Chalip 2004, 2018; O'Brien and Chalip 2006). Leveraging is defined as 'those activities which need to be undertaken around the event itself which seek to maximise the long-term benefit from events' (Chalip 2004, 228). The assumption underlying leveraging frameworks is that individuals and organizations managing events are doing so to achieve broader goals such as increased sport participation, access to sport, improved infrastructure, among others. However, this term has not received the same amount of attention among practitioners as legacy, and at this moment does not represent an adequate starting point for an investigation into the perspectives of event organizers and local officials. Furthermore, the effective leveraging of events requires an understanding of what goals the organizing bodies seek to achieve through event legacies, so that targeted efforts can be made to achieve these. Yet, the goal-setting among sport event organizers remains under-explored in the literature. This paper seeks to contribute to the literature by exploring the goals that organizers have for legacies in addition to their conceptualization of the legacy concept.

\section{Practitioners' perspectives of legacy}

While the academic literature proposed that legacy entails both positive and negative changes to the host-community (Preuss, 2007; Thomson et al. 2013), Cashman (2006) pointed out that this term may be understood as strictly positive by practitioners. Three recent empirical studies have specifically studied practitioners' perspectives of certain elements of event legacies. 
MacAloon (2008) explored the use of the term 'legacy' among Olympic administrators and found that it is often used to generate common, positive purpose among organizers. Sant, Mason, and Hinch (2013) interviewed destination marketers who worked in the context of reframing Vancouver as a sport destination following the Vancouver 2010 Olympic Games. These authors questioned their perceptions of the legacies of the event as this concept relates to the city image, finding that the destination marketers perceived legacies to be solely positive. Orr and Jarvis (2018) conducted an ex-ante set of interviews with members of the Toronto sport community over the anticipated sport legacies of Toronto 2015 Pan Am Games; not one respondent identified negative legacies. Hence, all three studies found evidence to support Cashman's (2006) claim that legacies are often seen as solely positive by practitioners.

Within legacy research, some studies have explored practitioner perspectives (MacAloon, 2008; Orr and Jarvis, 2018; Sant, Mason, and Hinch, 2013), and as reviewed above, each has offered valuable insight into important stakeholder perspectives of events. However, there remain two knowledge gaps for practitioner perspectives of legacy: (a) the specific perspectives of event organizers and legacy managers, who are responsible for planning and managing the legacies and can provide relevant insight into the positive/negative dimension (Parent 2008); and (b) practitioner conceptualizations of the other dimensions of legacy identified by Preuss (2007)—tangible/intangible, planned/unplanned, short-term/long-term, and local/global. Further, the goals associated with legacy planning and legacy management remain under-researched. These gaps led us to develop the following two research questions:

RQ1: How do event organizers (practitioners) perceive and understand event legacy? RQ2: What are event organizers' goals in relation to legacy?

\section{Methods}


Site

To address the research questions, a case study of a large-scale sport event held in Toronto, Ontario, was conducted. The fourth largest city in North America by population, Toronto is a dynamic and multicultural city with cultural influences from around the world (Galanakis, 2013). For example, in 2016, 51\% of Toronto residents are visible minorities, and $46 \%$ of residents in the city are immigrants (Statistics Canada, 2016). Like other large cities in North America, the cosmopolitan nature of the city fosters diverse political viewpoints (Qadeem, 2016). However, in the mid-2000s during the bidding period of the Toronto 2015 Pan Am Games, and during the hosting of the event, the Liberal Party of Ontario was in power. Interestingly, the Chair of the Bid Committee, who later became Chair of the Organizing Committee, David Peterson, was a former Premier of Ontario for the Conservative Party. This indicates bipartisan support for the event.

The Toronto 2015 Pan Am Games were held over two weeks in July of 2015 and welcomed over 6,000 athletes from 41 member-nations in the Pan American Sports Organization. Athletes competed in 35 sports, and the event received wide media attention in each media market across these nations. The 2016 Auditor General's report of the event estimates that the total cost of the event was CA $\$ 2.5$ billion (Lysyk 2016) and it created thousands of new jobs in the host city.

The Pan Am Games were planned by the Toronto 2015 Organizing Committee (hereafter also 'Organizing Committee'), a temporary organization of 25 full-time staff, based in downtown Toronto. The Organizing Committee was established expressly to plan and host the Games, and therefore was dismantled following the event. The Organizing Committee worked in close partnership with the City of Toronto, the Government of Ontario, and the Canadian Olympic Committee, which were the main funding and hosting partners. 
Toronto 2015 spurred capital improvements across the city in terms of both new facilities and upgraded facilities. The major capital projects built for the event were spread across the Greater Toronto Area and included: a new, world class field hockey centre (Pan American Hockey Center), two new state-of-the-art sport complexes (Markham Pan Am Center and the Aquatics Centre, Field House and Canadian Sport Institute Ontario based at the University of Toronto Scarborough Campus), two stadiums (a soccer stadium in Hamilton and an athletics stadium at York University), and an athletes village in downtown Toronto (Infrastructure Ontario, 2013). For each project, the Organizing Committee partnered with a municipal, university, or sport industry partner that would assume responsibility for the long-term maintenance and use of the facility after the event. Further and importantly, the Organizing Committee, along with its partner organizations, created long-term budget lines that would sustain the facilities' regular maintenance for up to twenty years after the event (Lorinc, 2015).

The Toronto Pan AM Games were also lauded for the social initiatives associated with the event, that included new murals and art installations throughout the city (Merringer, 2015), a Pride House during the event to promote and celebrate the queer community at the Games (Duong, 2015), and several unique coach-training initiatives hosted throughout the Province of Ontario and across the Americas (Toronto 2015, n.d.).

Despite the many positive legacies of the Toronto Pan Am Games, the event was also widely criticized on several operational and political shortcomings, including a financial overspend (Lysyk, 2016), a slow build process that compromised pre-event use of some facilities (Pagliaro, 2014), low ticket sales (Bascaramurty, 2015; Kuitenbrouwer, 2015), and political scandals including allegations of sexual misconduct within the Organizing Committee (Gibson and Benzie, 2017; Warren, 2015). Activists in the city protested the event on several occasions, 
critiquing the City and the Province for spending on an event instead of housing for homeless populations (Ruiter, 2015) and for potentially endangering sex workers in the city (Salerno, 2015). Members of the Latin American and Caribbean communities in Toronto, who stood to potentially benefit from hosting an event that celebrated their cultures of heritage and PanAmerican peace through sport, reported feeling 'left out' because of only superficial efforts made to include them (Loriggio, 2014). Evidently, the event had negative impacts, and members of the public were vocal in identifying these and expressing distaste.

As demonstrated by the examples above, Toronto 2015 had a mixed set of impacts and outcomes spanning each of Preuss' (2007) dimensions of legacy: positive and negative, planned and unplanned, tangible and intangible, short-term and long-term, and national and international. Considering that the topical focus of this case study is event legacies, Toronto 2015 appeared a rich case. Further, the familiarity of the first author with the city offered contacts and connections with city leadership that facilitated data collection.

\section{Data collection and analysis}

Semi-structured interviews $(N=10)$ were conducted with practitioners who worked on the event. We used semi-structured interviews because they support the interpretive paradigm and offer an opportunity to gain 'understanding of opinions, attitudes, experiences, processes, behaviours, or predictions' (Rowley 2012, 261). As we do not reside in the same region as the respondents, interviews were conducted over online video conferencing or phone, which is consistent with interview protocols of using flexible and opportunistic methods (Cresswell and Miller, 2010; Rowley, 2012).

Respondents included members of the Toronto 2015 Organizing Committee, Bid Committee, host jurisdictions, and organizations directly affiliated with the production of 
Toronto 2015 legacies. Purposive expert sampling was used to select interviewees who had direct experience with this event in the role of an organizer at one of the hosting bodies (host city offices, organizing committee, etc.). This sampling allows for a detailed understanding of the views, opinions, and knowledge of the respondents in relation to the research questions (Richie et al. 2013). Snowball sampling was also used: each respondent was asked if they could introduce other individuals who met our sampling criteria. After 10 interviews, we finished data collection as the same referrals were being offered and no additional data was produced.

Each interview lasted between 30 and 50 minutes, during which the respondents were asked to define legacy, and then answered questions about each dimension of legacy as defined in the academic literature (Preuss, 2007) to elicit a more directed response about the dimension, followed by a line of questioning related to legacy goals. The interview protocol is included in Appendix 1. Each interview was conducted by the first author, who transcribed verbatim for content analysis. The transcripts were then sent to the participants to check for accuracy before being analysed.

Using NVivo software, the first author deductively coded the interview transcripts following a thematic analysis including word-count and word-relation analyses (Fereday and Muir-Cochrane 2006), based on Preuss's (2007) dimensions of legacy. Subsequently, to validate findings through peer review and debrief (Creswell and Miller 2000), the codes were first confirmed by the second author. Next, they were shared with an external researcher (an expert in legacy research and coding methods) who independently coded the interviews using the set of codes produced by the first author and had the opportunity to create new codes, inductively, as they saw fit. The two coders agreed on $98 \%$ of the codes and resolved the few disagreements through discussion. 
In addition, a comparison with the academic literature was the final point of analysis, to find potential consistency and convergence between the practitioner perspectives and academic conceptualizations (Eisenhardt 1989). This was done using the findings of Thomson et al.'s (2013) comprehensive literature review on event legacies that identified the common dimensions and conceptualizations of the concept across the sport literature using Preuss's (2007) dimensions as a frame. This comparison allowed us to identify distinctive facets of the practitioners' perspective.

\section{Results}

Findings of RQ1

The coding process adopted Preuss's (2007) definition of legacy as a source for codes, and used 10 codes, representing the two poles of each of the five dimensions that Preuss identified in his definition: short-term, long-term, local, international, planed, unplanned, tangible, intangible, positive, and negative. Through the coding process, we found examples of only nine in the data set. The code not found in the transcripts was 'negative'. Table 1 summarizes the results of the interviews as framed by the five dimensions. Each dimension is discussed further below.

\section{[INSERT TABLE 1 HERE]}

\section{Positive/Negative}

In the positive/negative dimension, the respondents uniformly defined legacies as solely positive. Seven of the respondents could conceptualize that there would be some potential negative outcomes or impacts of the event, but they did not assign the term legacy to those negatives. For example, Respondent 3 explained: 
So, the legacies, when they're designed for the Bid Book at the beginning and developed throughout the hosting process, are always designed as positive outcomes. Not that there won't be negative outcomes, potentially, but those things like increased traffic are not usually measured by the Organizing Committee and they are not really legacies.

In describing negative outcomes of events, respondents used the term risk, instead of legacy: 'we have a risk framework to look at waste and negative impact' (Respondent 8). They also discussed these negative outcomes as being managed entirely separately from the legacies: 'anything that lasts beyond the Games could be negative, but if the Organizing Committee is doing its job properly, it will have that as part of its risk framework' (Respondent 4). This finding confirms and extends the earlier evidence provided by Orr and Jarvis (2018) and Sant, Mason and Hinch (2013) by demonstrating that practitioners do not recognize negative occurrences or outcomes as legacies.

\section{Planned/Unplanned}

In the planned/unplanned dimension, the respondents uniformly conceptualized legacies to be both planned and unplanned. For example, Respondent 1 discussed the unplanned beneficiaries of intangible benefits:

There are intended beneficiaries of our legacy projects which are the users, because that's what we're thinking of when we plan these. We're not actually thinking about the impact it'll have on them, or their little sibling who sees them excelling in sport and that kid thinks 'I'm going to work harder in school'... we just really don't know. You can't capture it all in your mind anyways. So, there are definitely, in my view, unintended legacies and beneficiaries. 
In this quotation, the respondent captures both poles of the planned/unplanned dimension, by explaining that the legacy projects of Toronto 2015 were indeed planned, but there may be unplanned legacies emanating from these planned legacies. This dimension is discussed explicitly in the academic literature (Preuss 2007; Thomson et al. 2013) using the same terminology as used by respondents in the interviews.

\section{Tangible/Intangible}

In the tangible/intangible dimension, all ten respondents discussed both poles. The terminology used was occasionally different: some respondents referred to these as hard (tangible) and soft (intangible) legacies. Respondent 5 discussed these tangible and intangible poles using examples, highlighting their presence across different categories of legacies:

There's a tangible legacy in terms of infrastructure, there's a tangible legacy in terms of programming that still exists that was developed in the Games context, there's the institutional relationships and knowledge and know-how that was developed, and that's softer, but also critically important. And then that would all cut across different dimensions: be it recreation, or economic development, or tourism focus, or housing focus.

The most common application of the term tangible was about new facilities or equipment, or new funding streams created for the Games. For intangible or soft legacies, almost all the examples offered were knowledge-related or psychological benefits to residents. There was little variety in the examples offered for the poles on the tangible/intangible dimension, though both were clearly and explicitly discussed by each respondent. The academic literature consistently references this dimension as tangible and intangible (Preuss, 2007; Thompson et al. 2013), so the 
conceptualizations of practitioners for this dimension correspond to how it has been conceptualized in the literature.

\section{Short-Term/Long-Term}

Nine of the ten respondents identified both short- and long-term legacies in their discussions, with only one respondent defining legacies as solely long-term. This was the dimension that had the most variability in how they were described. Some respondents spoke of immediate and long-lasting legacies; others used words like Games-time and enduring legacies. These terms can be distilled and coded as generally short-term and long-term. The starting point of legacies was left ambiguous by respondents: there was no definite sense in any of the interviews of a starting point for legacies, for example that they start before, during, or after the Games. For long-term legacies, examples included permanent structures, such as new sport facilities and new transit links, as well as long-term funding streams designed to last several years to fund the ongoing maintenance of programs and facilities. Respondent 2 stated that for the City of Toronto's office for Pan Am Games, the facility legacies will be long-lasting: 'from the City of Toronto perspective, we feel that the infrastructure that was developed for Pan Am has proven its worth and will be actively used for the 50 years.'

The short-term legacies were mainly conceptualized as Games-time legacies, or as legacies with definitive end-dates within a couple years of the event. For instance, Respondent 8 discussed the Play On! Parasport initiative that she deemed short-term, as it lasted only one year: 'The Play On! Funding program ended, that was just one year, but we do have other community funding programs. But that one, for community sport, was just one year.' Though nuanced in terms of timelines, there were examples offered by each respondent that were immediate, Games-time, or short-term, and others that were longer-term. This understanding of the 
dimension of time represents a slight variation in how academics conceptualize short-term legacy: academic literature positions short-term legacies as beginning after the event and having a short duration (Preuss 2007), whilst practitioners include games-time legacies in their conceptualization. Therefore, a spike in games-time tourism income for the host city may be considered a short-term legacy for the practitioners, though academics might disagree.

\section{Local/International}

The interview respondents uniformly identified local and international legacies, mostly within the context of legacies for Toronto and legacies for the Americas (i.e., the participating countries of the Pan Am Games). All ten respondents discussed the new facilities, infrastructure, and funding programs that will benefit Torontonians as examples of local legacies. Respondent 4 discussed some of these:

The UP Express that I mentioned, so the fixed-link to the airport, was another big one. There was some waterfront revitalization, so that City got on board and linked some of their waterfront revitalization with that, as did some of the other communities that hosted the Games. So, there were some local beautification projects that were all part of the processes of hosting games.

The international legacies were conceptualized as opportunities to improve the relationships between Canada and the participating countries, and in creating experiences for athletes from abroad to share the benefits of their participation with their families back home. In discussing the legacies for the sports community for the attending countries, Respondent 2 said:

Some of these countries, they get one vote, but they have 40,000 people, and they don't have budgets. So, what we did do is set aside money in the bid and during the games to assist their athletes. To train them, we sent trainers down there, we sent coaches down 
there, and we paid for them to come up, and in some cases, we helped them with equipment. So that was to help, shall we say, the Pan American sports movement. These findings of how practitioners understand the local/international dimension bear resemblance to how this dimension is conceptualized in the academic literature. In their review of legacy work published between 1991 and 2008, Thomson et al. (2013) referenced the local and global, rather than local and international. However, their discussion on this dimension is centred on the importance of considering the widest possible group of stakeholders by stating that 'events should be conceptualized in their broadest possible context to encourage stakeholder support and provide opportunities for legacies to be realized for the host city, as well as the wider region, nation, and beyond' (Thomson et al. 2013, 119). In the context of Toronto 2015, only 41 nations participated in the event (the countries of the Americas), and few nations outside this region had access to media broadcasts of the event. So, the widest scope of Toronto 2015 is better described as international, rather than global, with the latter being more appropriate in the context of the Olympics or FIFA World Cup.

Based on the findings, practitioners conceptualize legacies as positive, planned or unplanned, tangible or intangible, short-term (including Games-times) or long-term, and local or international. The absence of negative in the coding is consistent with Cashman's (2006) statement that organizers view legacies as solely positive, and with more recent studies that found that destination marketers and members of the sports community fail to acknowledge negative legacies (Sant, Mason and Hinch 2013; Orr and Jarvis 2018).

\section{Findings for RQ2}

In each interview, respondents were asked to explain what their organizations were trying to achieve through legacies. There were three themes that emerged from this line of questioning 
and illustrated their legacy goals. The first goal is to justify the public expenditures on the event. For instance, Respondent 2 explained: 'Legacy is the justification of the event, you need a justification for this, for spending public money on the Games.' Respondent 1 also stressed the importance of providing justification to the public, as much of the expenditure on the Pan Am Games, as well as on similar large-scale events, is taxpayer money:

But what's really important and what makes us good stewards of the public purse, is that these facilities will continue to work for residents and other people for 10, 20, 30 years down the road, and not just 2 weeks in July.

This finding offers evidence to support the claims of Cashman (2006), Chalip (2018), and Gold and Gold (2008) that organizers often justify their expenditures of events using legacies.

The second goal, mentioned by all ten respondents, is to promote and garner support for the event. Put simply, legacies were used as a marketing tool for the event. Respondent 6 explained the challenges in communicating the benefits of an event and the helpfulness of using legacies in this regard:

When you start out, that's all you have, right? You don't have buildings or anything yet, so you can't do the whole 'show, don't tell', because you don't have anything to show for the event when you're starting out. And so, you have to develop a sort of folklore of what the legacy will be.

In the case of Toronto 2015, as six respondents pointed out, some of the legacy projects were produced under the title of Host City Showcase. With the term showcase in the title, this program has a clearly indicated purpose of highlighting some of the city's offerings and promoting the City of Toronto. This supports a growing critique of legacy that it is just a buzzword intended to sell the event that is tired and overused (Chalip 2018). However, the 
evidence from the present study shows that this is only one of three goals from a practitioner's perspective, and hence only one piece of a larger puzzle that is legacy purpose.

The third goal espoused by all respondents was to meet policy and development goals at the city or provincial level. Respondent 10 began his definition of legacy by stating: 'the legacy component is a policy decision by the jurisdictions involved on what policy goals they'll accomplish through the Games.' By putting this goal at the beginning of his definition of legacy, this respondent made it clear that for host jurisdictions, city development and policy is of critical importance to the design and management of legacies. Respondent 5 explained that the City of Toronto had a goal for meeting city-development objectives through the Pan Am Games legacies: 'we had this mantra of 'plan and build the Games for the City, not the City for the Games'...So we wanted to design and plan the event for the longer-term city-building objectives of the city.' The city-development and policy goal is related to the other two goals in that the achievement of this goal could be used as a justification for hosting the event (goal 1) and lead to increased support for the event (goal 2).

Taken together, these three goals answer RQ2: the goals of practitioners for legacy is to justify public expenditures, to promote the event, and to meet policy and city-development objectives. Although the findings of this question are consistent with anecdotal evidence and speculation in previous works (Cashman 2006), this study is the first to explicitly ask organizers about what goals they seek to achieve through legacy plans and management and to offer empirical evidence of this.

\section{Discussion}

This study contributes to the ongoing discourse on event legacy within the sport, tourism, and leisure literature by exploring an alternative practitioners' perspective of legacies. Notably, the 
findings of this study, together with the findings of Orr and Jarvis (2018) and San, Mason and Hinch (2013), show that that the positive/negative dimension is understood to be solely positive by event organizers, and the dimension of time is understood by practitioners as including games-time positive impacts and outcomes. The findings also revealed that practitioners conceptualize legacies as planned or unplanned, indicating recognition that some aspects of legacy are beyond the organizers' control. Interestingly, respondents identified both tangible and intangible legacies, which is significant as it represents an appreciation for social and cultural legacies that may be more difficult to 'sell' in a bid or to a budgetary committee in government, but important to the public. As for the space dimension, respondents affirmed that legacies stretch beyond the host city which is interesting as the event is funded by the city and the province, and yet organizers are aware that the beneficiaries may be outside the region. In all, the dimensions of legacy are well understood by organizers and represent a positively-oriented view of legacies that stretches beyond the city limits, extends many years into future, and can be tangible or intangible.

This research contributes to the practice of sport event management, as the findings confirm previous research and crystallize the concept of legacy as positive in practitioner's view, thereby relegating all negative outcomes to other frameworks, such as risk assessment frameworks (Leopkey and Parent 2009a, 2009b). This will facilitate more directed management approaches that will allow event organizers to expand, promote, enhance and spread the benefits of positive legacies, while finding other frameworks that would help them to address the negative impacts and outcomes of the event. This will be especially important for organizers who wish to host a portfolio of events, and maintain the good reputation of the individuals and organizations involved in the planning and hosting each individual event within the portfolio. 
Understanding the legacy goals of event organizers is another important discovery as this explains, at least in part, why negative legacies would not be part of a practitioner's conceptualization of legacy. If the goals are to advance city development goals, boost public support for the event, and justify event expenditures, it would be counterproductive for organizers to discuss negative legacies. Additionally, the identification of these goals supports Chalip's (2018) recent calls to switch from 'legacy' to 'leveraging'; if organizers of events use legacies as a tool to increase public support and achieve other city development goals, they are effectively using a means-end rationale in which the legacies are used to leverage the positive outcomes of the event for the benefit of the host city, or host organization (Orr 1990; Van de Ven and Johnson, 2006).

A more honest discussion of legacies among event organizers, which encompasses both positive and negative legacies of an event, may be possible if the negative legacies were specifically prompted in bid documents. For instance, an event owner (e.g. the International Olympic Committee, the Pan-American Sports Organization) might begin to require a discussion of potential negative legacies such as noise, pollution, population displacement, and overspending, in the bid document. Further and importantly, other stakeholders such as city auditors, local organizations, and citizens ought to be consulted in legacy planning and legacy evaluation processes to ensure a broader range of perspectives and goals are represented in the legacy portfolio. This is particularly important in cases where events are funded by public dollars.

Although the current methodological approach allowed for an in-depth exploration of the organizers' perspectives and understandings of legacy, the study was limited in scope and generalizability because it used a single case. The findings should be revalidated in future 
research that extends the scope to other cases and a wider pool of interview respondents. Future research could also employ quantitative methods to assess the different perspectives among event organizers, and investigate the relationships between the different legacy dimensions. This study is also limited to organizers and does not consider other stakeholder groups, nor does it purport to represent the views of all practitioners.

Moreover, as the use of interviews and the interpretive lens allowed us to tease out the practitioners' perspectives and understandings of legacy, this same approach could be used in future research to understand how practitioners understand other sport and leisure concepts. By conducting research on practitioner conceptualizations and including these in the academic literature, academics can gain insight into perspectives that may otherwise be missed and that could inform the development of frameworks that can serve both practitioners and academics.

Since the 1990s, researchers have made remarkable efforts to advance the field's understanding of legacy, however important practitioner perspectives were previously underexplored. Legacy frameworks developed in isolation from practitioner perspectives are not making their way into the hands of those who need them, perhaps because they are unclear, or perhaps because there are potential inconsistencies between legacy conceptualizations of academics and practitioners, as our findings imply. It is our hope that this research will allow future researchers to develop frameworks that are more closely aligned with the perspectives of practitioners (e.g. positively framed and with a timeline that includes Games-time impacts) and thus translate easily to practice. Such practitioner-oriented frameworks may alleviate the burden of confusion surrounding legacies for event organizers. 


\section{References}

Bascaramurty, D. 2015, July 7. "Pan Am Organizers Try to Drum Up Support Amid Low Ticket Sales." The Globe and Mail. Retrieved online:

https://www.theglobeandmail.com/news/toronto/pan-am-organizers-trying-to-get-localsexcited-as-tickets-remain-undersold/article25344710/

Cashman, R. I. 2006. The Bitter-Sweet Awakening: The Legacy of the Sydney 2000 Olympic Games. Sydney: Walla Walla Press.

Chalip, L. 2004. “Beyond Impact: A General Model for Sport Event Leverage.” In Sport tourism: Interrelationships, Impacts and Issues, edited by B.W. Ritchie and D. Adair, 226-252, Clevedon: Channel View Publications.

Chalip, L. 2018. “Trading Legacy for Leverage.” In Legacies and Mega Events: Fact or Fairy Tales? edited by I. Brittain, J. Bocarro, T. Byers, T. and K. Swart, 25-42. New York: Routledge.

Chappelet, J.-L. 2012. “Mega Sporting Event Legacies: A Multifaceted Concept.” Papeles de Europa, 25, 76-86.

Creswell, J. W. and D.L. Miller. 2000. "Determining Validity in Qualitative Inquiry.” Theory into Practice, 39, 124-130.

Duong, S. 2015, June 25. Toronto to Host Pride House for Pan Am Games. Torontoist. Retrieved online: https://torontoist.com/2015/06/toronto-to-host-pride-house-for-pan-am-games/

Eisenhardt, K. M. 1989. "Building Theories from Case Study Research.” Academy of Management Review, 14, 532-550.

Fereday, J., and E. Muir-Cochrane. 2006. "Demonstrating Rigor Using Thematic Analysis: A 
Hybrid Approach of Inductive and Deductive Coding and Theme Development." International Journal of Qualitative Methods, 5, 80-92.

Galanakis, M. 2013. Intercultural public spaces in multicultural Toronto. Canadian Journal of Urban Research, 22 (1), 67-89.

Gibson, V. \& Benzie, R. 2017, October 31. "David Peterson Receives Apology as Sexual Harassment Lawsuit Thrown Out.” The Toronto Star. Retrieved online: https://www.thestar.com/news/queenspark/2017/10/31/former-premier-david-petersonreceives-apology-after-lawsuit-thrown-out.html

Gold, J. R., and M.M. Gold. 2008. "Olympic Cities: Regeneration, City Rebranding and Changing Urban Agendas." Geography Compass, 2, 300-318

Gratton, C. and H. Preuss. 2008. "Maximizing Olympic Impacts by Building up Legacies.” The International Journal of the History of Sport, 25, 1922-1938.

Infrastructure Ontario. 2013. Status of Major Venues for the Toronto 2015 Pan/Parapan American Games. Retrieved online: https://www.infrastructureontario.ca/FinancialClose-Backgrounder-Pan-American-Aquatics-Centrel

International Olympic Committee. 2015. Olympic Charter. Lausanne: International Olympic Committee.

Kassens-Noor, E., B. Maharaj, S. Müller, L. Huntoon, and M. Wilson. 2015. "Towards a MegaEvent Legacy Framework.” Leisure Studies, 34, 665-671.

Kuitenbrouwer, P. 2015, July 5. "Fears of a Pan Am Games Flop: Toronto Faces Empty Hotel Rooms, Unsold Tickets and Angry Locals.” Financial Post. Retrieved online: https://business.financialpost.com/news/economy/fears-of-a-pan-am-games-flop/

Leopkey, B. and M.M. Parent. 2009a. "Risk Management Issues in Large-Scale Sporting Events: 
A Stakeholder Perspective.” European Sport Management Quarterly, 9 (2), 187-208.

Leopkey, B., and M.M. Parent. 2009b. "Risk Management Strategies by Stakeholders in Canadian Major Sport Events.” Event Management, 13, 153-170.

Leopkey, B. and Parent. 2012. "The (Neo)institutionalization of Legacy and its Sustainable Governance within the Olympic Movement.” European Sport Management Quarterly, 12, 437-455.

Leopkey, B. and M. Parent. 2016. "The Governance of Olympic Legacy: Process, Actors, and Mechanisms.” Leisure Studies, 36 (3), 438-451.

Loriggio, P. 2014, July 11. "Cultural Communities Feel Left Out of Pan Am Games." Maclean's Magazine. Retrieved online: https://www.macleans.ca/news/canada/culturalcommunities-feel-left-out-of-pan-am-games/

Lorinc, J. 2015. "What Will Really Happen Once the Pan Am and Parapan Am Games are Over?” UTSC Commons. Retrieved online: utsccommons.utsc.ca/spring2015/features/after-games

Lysyk, B. 2016. “2015 Pan Amx/Parapan Games.” Toronto, ON: Office of the Auditor General. MacAloon, J.J. 2008. "Legacies as Managerial/Magical Discourse in Contemporary Olympic Affairs." The International Journal of the History of Sport, 25 (14), 2060-2071.

Merringer, I. 2015, June 19. "Pan Am Path Knits an Underworld Within Toronto.” The Globe and Mail. Retrieved online: https://www.theglobeandmail.com/news/toronto/pan-ampath-knits-an-underworld-within-toronto/article25041629

Müller, M. 2014. “After Sochi 2014: Costs and Impacts of Russia’s Olympic Games.” Eurasian Geography and Economics, 55, 628-655. 
O'Brien, D. and L. Chalip. 2007. "Executive Training Exercise in Sport Event Leverage." International Journal of Culture, Tourism and Hospitality Research, 1, 296304.

Orr, J. E. 1990. "Sharing knowledge, celebrating identity: Community memory in a service culture." In Collective Remembering, edited by D. Middleton and D. Edwards, 168-189. London: Sage.

Orr, M. and N. Jarvis. 2018. "Blinded by Gold: Toronto Sports Community Ignores Negative Legacies of Pan Am Games.” Event Management, 22 (3), 367-378.

Pavoni, A. 2015. "Resistant legacies". Annals of Leisure Research, 18 (4), 470-490.

Pagliaro, J. 2014, July 13. "Pan Am Games Hampered by Facility Delays." The Toronto Star. Retrieved online: https://www.thestar.com/news/gta/panamgames/2014/07/13/pan_am_games_hampered_b y_facility_delays.html

Parent, M. M. 2008. "Evolution and Issue Patterns for Major-Sport-Event Organizing Committees and their Stakeholders." Journal of Sport Management, 22, 135-164.

Qadeem, M.A. (2016). “Multicultural Cities: Toronto, New York, and Los Angeles.” Toronto: University of Toronto Press.

Preuss, H. 2007. "The Conceptualisation and Measurement of Mega Sport Event Legacies." Journal of Sport \& Tourism, 12, 207-228.

Preuss, H. 2015. “A framework for identifying the legacies of a mega sport event.” Leisure Studies, 34, 643-664.

Rowley, J. 2012. “Conducting Research Interviews.” Management Research Review 35, 260-271. 
Ruiter, Z. 2015, March 11. "Pan Am Games Torched.” Now Magazine. Retrieved online: https://nowtoronto.com/news/pan-am-games-torched/

Salerno, R. 2015, March 26. "Sex, Shelter and the Pan Am Games." Now Magazine. Retrieved online: https://nowtoronto.com/news/sex-shelter-and-the-pan-am-games/

Sant, S. L., D.S. Mason, and T.D. Hinch. 2013. “Conceptualising Olympic Tourism Legacy: Destination Marketing Organisations and Vancouver 2010.” Journal of Sport \& Tourism, 18 (4), 287-312.

Statistics Canada. 2017. "Toronto [Census metropolitan area], Ontario and Ontario [Province] (table)". Statistics Canada Cataologue no 98-316-X2016001. Retrieved online: https://www12.statcan.gc.ca/census-recensement/2016/dp-pd/prof/index.cfm?Lang=E

Thomson, A., G. Cuskelly, K. Toohey, M. Kennelly, P. Burton, P., \& L. Fredline. 2018. Sport event legacy: A systematic quantitative review of literature. Sport Management Review.

Thomson, A., K. Schlenker and N. Schulenkorf N. 2013. "Conceptualizing Sport Event Legacy." Event Management, 17, 111-122.

Toronto 2015. nd. "Community Initiatives.” Retrieved online: www.toronto2015.org/aboutus/community-initiatives

Van de Ven, A. H. and P.E. Johnson. 2006. "Knowledge for Theory and Practice." Academy of Management Review, 31, 802-821.

Warren, M. 2015, October 30. "Despite Canadian Laws, Strategies, and Sex Campaigns, Cases and Allegations of Sexual Harassment Keep Coming Out." The London Free Press. Retrieved online: https://fpress.com/2015/10/30/despite-canadian-laws-strategies-and-campaigns/ 
Appendix 1

\section{Interview Protocol}

Legend: Question (purpose of the question)

1. Can you confirm your position at the time of the Toronto Pan Am Games? (validate their participation in the study and relationship to the case)

2. How would you describe 'legacy' based on your experience? (explicit definitions and conceptualizations)

3. Can you give me examples of Toronto Pan Am legacies? (implicit discussion of the dimensions and classifications of legacy)

4. Was there a designated 'legacy' staff person or team within your organization? What was their job description? (alludes to planning and management of legacies)

5. Was the legacy staff person/team also responsible for negative impacts of the event? Or was that handled by another person or team? (alludes to management of legacies vs negative impacts/outcomes)

6. In the bid document, press releases for the event, and meeting minutes, legacies are discussed in some detail, but there is no mention of any negative event-related incidents, impacts or outcomes. What factors do you think contributed to this omission?

a. Is this because legacies are largely managed and promoted as the positive impacts and outcomes, and the negative consequences of events are managed and communicated to the public differently? (alludes to the differences in $+/$ - outcomes and impacts)

7. What are the legacies intended to achieve? (alludes to the rationale for having legacies at all)

8. What goals did you have in mind for the legacies for the event during the planning phase? During the event itself? After the event? Did the goals ever change or were they consistent? (to understand what goals were set and the motivation for the legacy portfolio at various stages of the hosting effort)

9. Is there anybody else you can think of who may be a good respondent for this study? (potential for snowball sampling) 
Table 1

A Summary of Interview Results

\begin{tabular}{|c|c|c|c|c|c|}
\hline $\begin{array}{l}\text { Respondent Identifier \& } \\
\text { Affiliations }\end{array}$ & $\begin{array}{l}\text { Positive/ } \\
\text { Negative } \\
\text { Dimension }\end{array}$ & $\begin{array}{l}\text { Tangible/ } \\
\text { Intangible } \\
\text { Dimension }\end{array}$ & $\begin{array}{l}\text { Planned/ } \\
\text { Unplanned } \\
\text { Dimension }\end{array}$ & $\begin{array}{l}\text { Short-term/ } \\
\text { Long-term } \\
\text { Dimension }\end{array}$ & $\begin{array}{l}\text { Local/Internati } \\
\text { onal } \\
\text { Dimension }\end{array}$ \\
\hline $\begin{array}{l}\text { Respondent } 1 \text { - City of } \\
\text { Toronto; Pride House } 2015\end{array}$ & Positive & $\begin{array}{l}\text { Tangible/ } \\
\text { intangible }\end{array}$ & $\begin{array}{l}\text { Planned/ } \\
\text { unplanned }\end{array}$ & $\begin{array}{l}\text { Short-term/ } \\
\text { long-term }\end{array}$ & $\begin{array}{l}\text { Local/Internati } \\
\text { onal }\end{array}$ \\
\hline $\begin{array}{l}\text { Respondent } 2 \text { - Bid } \\
\text { Committee for Toronto } \\
\text { 2015; Toronto } 2015 \\
\text { Organizing Committee }\end{array}$ & Positive & $\begin{array}{l}\text { Tangible/ } \\
\text { intangible }\end{array}$ & $\begin{array}{l}\text { Planned/ } \\
\text { unplanned }\end{array}$ & Long-term & $\begin{array}{l}\text { Local/Internati } \\
\text { onal }\end{array}$ \\
\hline $\begin{array}{l}\text { Respondent } 3 \text { - Ontario } \\
\text { Ministry of Tourism, Culture } \\
\text { and Sport }\end{array}$ & Positive & $\begin{array}{l}\text { Tangible/ } \\
\text { intangible }\end{array}$ & $\begin{array}{l}\text { Planned/ } \\
\text { unplanned }\end{array}$ & $\begin{array}{l}\text { Short-term/ } \\
\text { long-term }\end{array}$ & $\begin{array}{l}\text { Local/Internati } \\
\text { onal }\end{array}$ \\
\hline $\begin{array}{l}\text { Respondent } 4 \text { - Toronto } \\
\text { Foundation }\end{array}$ & Positive & $\begin{array}{l}\text { Tangible/ } \\
\text { intangible }\end{array}$ & $\begin{array}{l}\text { Planned/ } \\
\text { unplanned }\end{array}$ & $\begin{array}{l}\text { Short-term/ } \\
\text { long-term }\end{array}$ & $\begin{array}{l}\text { Local/Internati } \\
\text { onal }\end{array}$ \\
\hline $\begin{array}{l}\text { Respondent } 5 \text { - City of } \\
\text { Toronto }\end{array}$ & Positive & $\begin{array}{l}\text { Tangible/ } \\
\text { intangible }\end{array}$ & $\begin{array}{l}\text { Planned/ } \\
\text { unplanned }\end{array}$ & $\begin{array}{l}\text { Short-term/ } \\
\text { long-term }\end{array}$ & $\begin{array}{l}\text { Local/Internati } \\
\text { onal }\end{array}$ \\
\hline $\begin{array}{l}\text { Respondent } 6 \text { - Toronto } \\
2015 \text { Organizing Committee }\end{array}$ & Positive & $\begin{array}{l}\text { Tangible/ } \\
\text { intangible }\end{array}$ & $\begin{array}{l}\text { Planned/ } \\
\text { unplanned }\end{array}$ & $\begin{array}{l}\text { Short-term/ } \\
\text { long-term }\end{array}$ & $\begin{array}{l}\text { Local/Internati } \\
\text { onal }\end{array}$ \\
\hline $\begin{array}{l}\text { Respondent } 7 \text { - Toronto } \\
2015 \text { Organizing Committee }\end{array}$ & Positive & $\begin{array}{l}\text { Tangible/ } \\
\text { intangible }\end{array}$ & $\begin{array}{l}\text { Planned/ } \\
\text { unplanned }\end{array}$ & $\begin{array}{l}\text { Short-term/ } \\
\text { long-term }\end{array}$ & $\begin{array}{l}\text { Local/Internati } \\
\text { onal }\end{array}$ \\
\hline $\begin{array}{l}\text { Respondent } 8 \text { - City of } \\
\text { Toronto }\end{array}$ & Positive & $\begin{array}{l}\text { Tangible/ } \\
\text { intangible }\end{array}$ & $\begin{array}{l}\text { Planned/ } \\
\text { unplanned }\end{array}$ & $\begin{array}{l}\text { Short-term/ } \\
\text { long-term }\end{array}$ & $\begin{array}{l}\text { Local/Internati } \\
\text { onal }\end{array}$ \\
\hline $\begin{array}{l}\text { Respondent } 9 \text { - Ontario } \\
\text { Ministry of Tourism, Culture } \\
\text { and Sport }\end{array}$ & Positive & $\begin{array}{l}\text { Tangible/ } \\
\text { intangible }\end{array}$ & $\begin{array}{l}\text { Planned/ } \\
\text { unplanned }\end{array}$ & $\begin{array}{l}\text { Short-term/ } \\
\text { long-term }\end{array}$ & $\begin{array}{l}\text { Local/Internati } \\
\text { onal }\end{array}$ \\
\hline $\begin{array}{l}\text { Respondent } 10-\text { Pan / } \\
\text { Parapan American Games } \\
\text { Secretariat (Province of } \\
\text { Ontario) }\end{array}$ & Positive & $\begin{array}{l}\text { Tangible/ } \\
\text { intangible }\end{array}$ & $\begin{array}{l}\text { Planned/ } \\
\text { unplanned }\end{array}$ & $\begin{array}{l}\text { Short-term/ } \\
\text { long-term }\end{array}$ & $\begin{array}{l}\text { Local/Internati } \\
\text { onal }\end{array}$ \\
\hline
\end{tabular}

